\title{
Introduction to the Handbook of Teaching and Learning at Business Schools
}

According to the World Economic Forum (2019), the severe challenges confronting higher education - including the need for lifelong learning, students acting like consumers, technological advances, and an increasing focus on skills rather than degrees - mean that its delivery must change for the future. To this list of challenges we add an increased political and institutional focus on teaching and its impacts, as well as the insufficiencies of the business models currently embraced by mass universities. We consider their implications in turn.

\section{LIFELONG LEARNING}

Rapid technological and social changes require people to update their knowledge throughout their careers; in turn, education models must meet this demand for lifelong learning. For workers likely to undertake multiple careers, new skills are prerequisites of remaining relevant in labor markets. Universities must reject a dominant model that suggests they can provide a comprehensive education to younger adults. Their activities and structures instead must reorient toward continuous learning, implying substantial reconsideration of their activities and structures, as well as a novel capacity to adapt to learners with divergent levels of experience and competence.

\section{STUDENTS AS CONSUMERS, WITH SPECIAL NEEDS AND EXPECTATIONS}

If governments identify students as consumers, who pay tuition fees and demand a service in return, higher education institutions must address market forces, including competitiveness, efficiency and customer satisfaction. Students embrace this consumer identity too, leading them to demand more from higher education service providers and gauging the value for their money. If students are customers who make their educational decisions on the basis of their economic self-interest, interesting questions emerge about their perceptions of higher education assessment too. But students also call for personalized, collaborative relationships with their university, rather than conventional or superficial consumer transactions. The challenge for universities is to find ways to leverage market competition to enhance the teaching practices they provide and the learning outcomes their "consumers" receive in the long term.

\section{TECHNOLOGICAL ADVANCES}

Two key technological trends are particularly relevant for universities. First, developments in robotics, artificial intelligence and machine learning alter the demands of the workforce. 
In university settings, machines might grade student assignments, and if artificial intelligence takes responsibility for other human functions, then universities need to rethink what students should learn to be able to contribute to society. They need "robot-proof" human knowledge. Second, new learning technologies, such as online courses, simulation games, virtual learning and online learning platforms, provide new means to promote learning in varied settings. These technologies have attractive benefits, in that they offer a way to transmit knowledge with minimal costs compared with traditional formats, even as they promise to improve students' technological literacy. Rather than solely replacing humans, these technological trends offer opportunities for redefining professions and disciplines, assuming some knowledge transmission can occur through technological platforms and thereby freeing up in-class time for other teaching priorities and learning opportunities.

\section{FOCUS ON SKILLS RATHER THAN DEGREES}

Business students traditionally sought a degree. Today, the degree is still important, but the focus is shifting toward the achievement of relevant skills, driven by two main factors. First, university education historically was exclusive, such that relatively few people had access to it. But once-prevalent quotas on how many students may be admitted to universities have been repealed in most nations, and substantial new universities (especially private and online ones) have opened. Thus it has become far easier to find employees with a business degree, but that means a degree is no longer a sufficient condition to ensure a good job. Therefore, business students demand that universities provide them with skills and abilities that differentiate them from other candidates. Second, business research and education suffer a relevance problem. A lot of knowledge is being created and conveyed to the students, but its real-world effectiveness remains poorly documented. Firms do not regard a business degree as proof of necessary skills to do the job. Instead, potential employers turn to various tools to predict the quality of prospective employees (e.g., probation periods, in-house and third-party tests, multi-round interviews). Then, once hired, they provide employees with the skills they want them to have, using on-the-job and in-house training programs. These firms are bringing the functions traditionally outsourced to business schools back in house, which means business schools have a renewed need to demonstrate, to students and potential employers, the value and effectiveness of the education they provide and thereby establish their basic legitimacy.

\section{POLITICAL AND INSTITUTIONAL FOCUS ON TEACHING AND ITS IMPACTS}

At a global level, political entities and institutions across societies pay more attention to teaching and its impact on students, manifested in new legislation and accreditation frameworks. For example, in 2019, new Danish legislation required all universities to ensure the continuous professional development of their teachers, regardless of their seniority. Accreditation frameworks for teaching excellence, such as the United Kingdom (UK) Professional Standards Framework, are spreading throughout higher education facilities, such as to Copenhagen Business School, where faculty at all levels are encouraged to seek fellowship awards within this framework. This political and institutional focus on professional development and teach- 
ing excellence is not an end unto itself, but it imposes more evidence-based routes toward optimal learning outcomes. As a consequence, virtually all faculty will be forced to reconsider their own modus operandi in designing and delivering teaching, such as by embracing student-centered learning designs wholly.

\section{MASS UNIVERSITIES' BUSINESS MODELS}

The number of universities distributing business degrees is increasing. With the arrival of new technologies, such as online learning, business schools' abilities to reach students also is increasing. Lockdowns imposed during the COVID-19 pandemic made online education even more legitimate and appealing. Overall, then, business schools are facing unparalleled competition, both within the industry and externally. Because of the lack of knowledge about the actual effectiveness of business education, several alternative service providers (e.g., certification programs by large corporations) have moved into this space. With big data, cheaper, less time-consuming and more effective methods for providing business education also could be developed. To survive, then, business schools must find ways to deal with intra-industry competition (e.g., mergers and alliances) but also anticipate inter-industry competition (e.g., more advanced and effective teaching methods).

\section{CONTRIBUTIONS}

The objective of this Handbook is therefore to investigate multiple angles from which to consider teaching and learning in business school. Together, the chapters fill gaps in prior research, but they also explore and expand new fields. The Handbook's 25 chapters are divided into seven parts:

Part I: Transformational Perspectives.

Part II: Learning Environments.

Part III: The Use and Value of Learning Technologies.

Part IV: In the Business School Classroom.

Part V: Leadership Education.

Part VI: Continuous Professional Development of Research-Based Teachers.

Part VII: Bridging Teaching, Research and Practice.

\section{PART I: TRANSFORMATIONAL PERSPECTIVES}

Rapidly changing societal and workplace requirements necessitate new options for designing and delivering business school programs. In dynamic business landscapes, marked by new opportunities, uncertainty and risk, business schools confront the strategic need to rethink their changing role, reflecting globalization, competition and technological advances. Traditional models and processes, designed to support academically isolated operations, need to be re-evaluated, as should the traditional offering of a fixed degree, such as a flagship MBA. To replace this increasingly irrelevant offer, inventive models of education should focus more on 
the responsibility to educate responsible leaders. In Part I, the contributions suggest reimagining pedagogical models, building relations, and collaborating with industry and society to provide more impactful educational offerings for a sustainable future.

For example, to meet their responsibility to contribute to the well-being of communities, Kreber, Wardley, Leviten-Reid, and MacPherson (Chapter 1) argue that business schools should offer an intentionally transformative education, such that students develop identities as change agents, capable of achieving a fairer, more sustainable future. In proposing "Community-engaged learning in business schools to effect social change: capabilities perspective," these authors call for a new view of the purpose of business education that reveals a different set of desirable learning outcomes, then defines the pedagogical practices that can produce those outcomes. In illustrating the proposed capabilities development model for higher education, distinct from a human capital development model, this chapter describes how Cape Breton University developed community-engaged experiential learning opportunities. Rather than ideal cases, these examples provide foundations on which to build.

A co-design model offers another alternative for addressing shifts in higher education and achieving strategic pedagogical change, as Wilson, Huber and Bryant (Chapter 2) propose in "Using co-design processes to support strategic pedagogical change in business education." With a focus on the changing roles of educational developers and learning designers, this chapter outlines co-design processes that involve multiple stakeholders, as exemplified by the Connected Learning at Scale initiative at University of Sydney Business School. The analysis reveals some guiding principles and paradoxes that produce a range of impacts and outcomes that can inform efforts by various universities to design methods to meet the challenges and opportunities they face.

In another study set in Australia, Mantai (Chapter 3) investigates the "Benefits and challenges of Assurance of Learning: making the intangible tangible." In an Assurance of Learning (AoL) process, measures of students' achievement of each program goal inform all future program decisions and designs. This reflective account of the benefits and challenges of applying AoL to business schools identifies the need for more effort devoted to operational aspects (i.e., measuring and reporting) rather than to closing the loop. In particular, curriculum design, staff development and genuine stakeholder engagement efforts are what lead to a well-developed AoL system. However, program directors also must recognize that AoL practices constantly evolve, reflecting the constant change and vast complexity of higher education.

\section{PART II: LEARNING ENVIRONMENTS}

Environmental variables also inform cognitive processes, such that at both individual and collective (e.g., team) levels of analysis, knowledge acquisition and application depend on the contextual factors. In classrooms, the characteristics of the learning environment determine student motivation, satisfaction and performance. To identify the best classroom designs, such that they facilitate learning by business students, the studies in Part II combine both theoretical and practical insights to delineate several factors that instructors and business schools should include in their learning environments to improve student-related outcomes.

Arendt and Christensen (Chapter 4) propose a studio concept, noting that studios historically provided critical sites for design and architecture learning and increasingly appear in business schools and other institutions of higher learning too. In "The promise of the business studio: 
teaching for design and entrepreneurship at business schools," they suggest its relevance as a space in which design pedagogics can inform business and entrepreneurship courses in business schools. A business studio encourages iterative, make-and-reflect processes and hands-on learning, which should enhance student engagement and encourage more active, deeper learning. The resulting skills are clearly in demand in contemporary labor markets. With three examples of teaching in the business studio at Copenhagen Business School, they offer recommendations for developing business studios elsewhere.

With an empirical, grounded theory approach, Kember (Chapter 5) derives a motivational teaching and learning environment framework, based on 36 interviews with undergraduate students, in which they reported on what motivated them to learn. The result, namely, "A framework for motivating business students through teaching, learning and curriculum design," contains eight facets, which this chapter illustrates with verbatim comments from students in business, hospitality and tourism management. It offers a practical guide to teaching and learning to motivate students.

Complimenting the student interviews in the previous chapter, "The challenge of reflexive pedagogy in executive education: a personal case study" reflects the author's perspective as an educator. Iszatt-White (Chapter 6) takes a critical view on reflexive pedagogy, despite a popular view that considers it universally desirable, due to the associated challenges of a sense of "identity undoing" during the shift from content expert to process facilitator. A sense of "unknowability" may also emerge when control for the direction and content of the learning gets assigned to the learner, which upsets the conventional power asymmetry of learning interactions. The author thus recommends that educators carve out their own sense of purpose and ability, which enables them to contribute in conjunction with students' active efforts.

Another popular pedagogical topic, team-based learning (TBL), promises to enhance student engagement by resolving issues associated with traditional group work. But these promises might come in for challenge, as Larson and Sweet (Chapter 7) consider when they seek to determine how and to what extent TBL needs to be adapted to match the individual instructors and their classrooms. In "Team-based learning in the business school classroom: adaptation versus fidelity," they note a tension between adaptation and orthodoxy, then outline some justifications for the variety of adaptations they find in practice. By integrating conceptual discussions of treatment fidelity and the diffusion of innovation, they specify some risks of adaptation too. This nuanced approach identifies essential factors that TBL instructors should be sure to retain.

\section{PART III: THE USE AND VALUE OF LEARNING TECHNOLOGIES}

In addition to new approaches, learning technologies strongly influence the way teaching is planned and delivered. Consider a historical example. When chalk was replaced by overhead projectors, a trade-off emerged between the efficiency of reusing teaching slides versus the spontaneous creative content mapping that could happen on the blackboard. More recent technologies continue to revolutionize learning in higher education, as videos, podcasts, simulations, online feedback and online quizzes have broadened the pedagogical toolbox. But as the contributions to Part III highlight, teaching technologies are not just useful tools for content delivery: they change the way teaching gets planned and the way learning outcomes 
are assessed. Their use and value thus must be carefully assessed before they are adopted in any course design. To this end, the three contributions in Part III discuss the uses and value of learning technologies underlying blended learning, gamified learning in teams, and business school curricula.

For example, Kjærgaard, Thomsen and von Wallpach (Chapter 8) present "Transformations toward blended learning: key issues to address," with a list of assertions that can inform faculty who are considering blended learning. The authors propose that blended learning is not a single pedagogy; rather, it should combine the best practices of multiple domains, which can be achieved if its developers focus on learning rather than technology. In the new learning opportunities created by blended learning, interactions are both facilitated and limited, which creates a powerful need for both organizational and personal adaptation. The authors describe their own experiences with blended learning, as teachers, consultants and administrators, which leads them to assert that addressing these key issues can limit misunderstandings of how blended learning can promote student learning, but also the gaps it cannot address.

Plé and Koles (Chapter 9) offer a different sort of caution, arguing that rather than limiting investigations of the influence of technology to course delivery or course design, researchers also need to address its impact on assessments and course content. Such an approach reflects three pillars of a comprehensive learning experience: pedagogy, assessment and content. Thus "The influence of technology on business schools' curricula: a triple crown perspective" offers a framework that describes which technological solutions can advance student learning journeys. It also acknowledges some challenges linked to technologically infused curricula that, if addressed effectively, can even become opportunities.

The last chapter in Part III deals with "Gamification in education: the case of gamified learning in teams." Concerned that prior literature tends to focus only on how gamified learning informs individual student experiences, not interpersonal or team factors, Khusainova, Sahhar and De Jong (Chapter 10) conduct a study with a real game, available to multiple universities, and gather student and instructor narratives. The results affirm their assertion that interpersonal and team dynamics are critical, so the key dimensions they list can help instructors successfully implement and maintain games for their own courses.

\section{PART IV: IN THE BUSINESS SCHOOL CLASSROOM}

Regardless of how much they integrate technology, though, diverse business school classrooms require effective strategies for teaching, delivered by dedicated instructors. In considering demands for high-quality teaching in higher education, the authors in Part IV offer meaningful reflections on multiple aspects of the practice.

Lecturing is one of the oldest methods of teaching, and Greve (Chapter 11) in "Lecturing" provides a comprehensive review of the genre, as well as the affordances and constraints of giving good lectures. To understand this widespread and widely debated teaching format, she investigates large-scale lectures provided by a business school and introduces a taxonomy of lecturing with three archetypes: soundtrack lecture, interaction lecture and engagement lecture. But a successful lecture depends not on its approach or type, but rather on the relation it creates between the lecturer and students, the quality of their interaction, and the added value attained by attending a lecture. 
In "the case for cases: using historical and live cases to enhance student learning," Moolenaar and Beverland (Chapter 12) investigate the long history of using case studies for education. Despite some challenges, they continue to offer value for business education, both in class and online. By leveraging their decades of international case development and teaching experiences, these authors introduce several different case types and their purpose. Packed with practical advice for educators, this chapter also provides a compelling argument for traditional paper-based or video-driven cases, as well as live, real-time cases. It contains advice for running cases online or in a blended learning environment.

Rosier (Chapter 13) concurs with Moolenaar and Beverland's perspective, with regard to the use of live projects as a means to encourage students' employability skills. In "Using live business projects to develop graduate employability skills," she gathers students' perceptions of their own skills, using both quantitative and qualitative data, and finds significant changes over time. That is, instructors can help students develop self-management, communication, teamworking, problem-solving and organization skills, as well as enhance their confidence. These insights into a relevant experiential learning approach encourage more learning environments in which students interact with real businesspeople during live projects.

In addition to ensuring students gain employability skills, instructors must offer them direct assessments and feedback, a challenge that appears inherent to higher education. In "Addressing the challenges of assessment and feedback in business schools: developing assessment practices that support learning," Reimann, Sambell, Sadler and Kreber (Chapter 14) cite a paradigm shift, triggered by student dissatisfaction, that altered models of assessment. To support learning, they call for assessment for learning techniques which reflect contemporary concerns and practices of business educators. These techniques prioritize authenticity; they also might be expanded to find innovative assessment and feedback practices. With several vignettes, the authors suggest ways to implement these methods in practice.

Finally, noting that experiments with studio-based inquiry draw inspiration from professional art and design schools, Meisiek (Chapter 15) in "Business studios of practice" argues for a studio approach to bridge traditional divisions in situated learning. That is, it usually refers to either higher education or work and the organization, but a business studio attempts to combine them in a learning space that draws on art, design and craft traditions to encourage innovation in business school settings. The practices it encourages then can enable graduates to participate in communities of practice in their future workplaces. With reference to the Studio at Copenhagen Business School, this chapter leverages activity theory and habits of mind to assert that business studios, as settings for emergent activity, help participants develop necessary practices for future jobs.

\section{PART V: LEADERSHIP EDUCATION}

Developing future leaders is a key goal of any business school, both to benefit society by educating students who can accomplish a variety of tasks, and to benefit students themselves. Most well-paid jobs tend to involve leadership, so business students, as consumers, demand that their schools help them prepare to undertake these desirable roles. Among the substantial research devoted to leadership, most of it is rooted in psychology literature, not pedagogy research. In turn, two topic areas tend to focus on who will emerge as successful leaders (trait perspective) or which circumstances help people emerge as successful leaders (social psychol- 
ogy perspective). What is missing is insights into how to encourage people to develop and emerge as successful leaders. The chapters in Part V aim to provide evidence related to how business schools can educate students so that they become successful future leaders.

As Nicholds (Chapter 16) puts it, allegations by management critics that "business schools have lost their way" suggest failures to prepare graduates effectively. She therefore proposes a critical approach to teaching leadership, such that by being critically reflexive about the value and applicability of business theory, business schools can engage in, as the chapter title puts it, "Building a new identity for business schools: learning how to act with authenticity through the critical teaching of leadership." Support for student leaders in the classroom requires helping them understand the contested nature of leadership concepts, so that they can reflect critically on the impacts of their professional practice on organizational outcomes. Embracing this recommended approach, Nicholds offers personal reflections on how this delivery has affected her identity as an academic and practitioner, as well as some unique contributions toward wider societal goals.

Prior literature on leadership development, leader identity and learning from experience offers some notable insights, which Zaar, Van Den Bossche and Gijselaers (Chapter 17) integrate in a guiding framework in "New avenues for leadership education and development: shaping leader identity through meaning-making from experiences." Focused on deeper-level, cognitive elements of leadership, they suggest that meaning-making, derived from experiences, can promote students' leadership development by shaping their leader identities. In turn, leadership education should purposefully leverage classroom experiences to encourage students' identities as leaders, because doing so establishes a foundation for continued leadership development.

Along with such a foundation, business leaders need relevant enterprise skills, capabilities and attributes. In "Equipping students with the attributes needed by business leaders in an era of social and technological change," Kember (Chapter 18) conducts focus group interviews with students to learn which graduate attributes they thought they needed and could develop. Two broad categories emerge: intellectual capabilities and capabilities for working together, which include critical thinking, self-managed learning, problem-solving, adaptability, communication, interpersonal skills and group work. To nurture such attributes, they also believed the teaching and learning environment should provide opportunities to practice using the key capabilities. In turn, the environment should include active learning (to provide practice opportunities), teaching for understanding (to address certain topics in depth), assessment (based on exhibitions of key attributes) and cooperative learning (practice working together).

\section{PART VI: CONTINUOUS PROFESSIONAL DEVELOPMENT OF RESEARCH-BASED TEACHERS}

The diverse student populations inhabiting higher education institutions vary widely in their ages, ethnicities and cultures, as well as their prior experience. A student who has been working for several years will want a different education than one who is fresh out of high school. Furthermore, students spending considerable sums on tuition fees, as well as board and accommodation, demand a top-notch education, devoted to their individual needs, not to the average student. Universities also compete for better rankings in (inter)national university assessments, which in turn are based largely on student satisfaction. Thus, universities are 
reorienting their attention, including developing professional development programs with a view to make academics into better educators. Some programs leverage technological developments that allow teachers to present materials, and students to engage with those materials, in new ways. Other technological developments help universities facing reduced state funding by making it possible for academics to cover larger classes. With Part VI, the contributors consider additional ways to encourage academics to embrace continued professional development.

Setting their contribution in the context of German universities, Wilkesmann and Lauer (Chapter 19) note two key developments: steering instruments introduced on the basis of new public management (transactional governance), and devoted efforts to enhance teaching culture (transformational governance). In "How to motivate professors to teach," they consider these opportunities for universities to exert top-down influences on teaching-related behaviors. According to survey data, transformational governance efforts have positive effects on teaching commitment, but the transactional steering instruments do not. Overall, though, between 2009 and 2016, teaching motivation has changed, such that high-quality teaching informs professors' self-esteem, and guilt arises if they neglect teaching duties.

In relation to associate professors specifically, as a crucial cohort for modern business schools, Irwin (Chapter 20) describes the Associate Professor Development Programme (APDP) at Copenhagen Business School as a pertinent method for enhancing research (including funding), teaching and administrative efforts. This assessment, "Teaching and learning with our colleagues: the Associate Professor Development Programme at Copenhagen Business School," reveals some key lessons. Despite questions and challenges related to the APDP design and operations, it has provided valuable space for reflection and identification of practical career development options. Furthermore, the APDP encourages a sense of identity and academic citizenship throughout the business school.

Many scholars express an interest in diversity; the key is finding ways to ensure they are leveraging diversity in the classroom. Villesèche and Teilmann-Lock (Chapter 21), in "Leveraging Diversity in the Classroom," describe and reflect on the development of such a course, for which they took a design thinking approach. By outlining the class materials, course structure, key features, and exercises and activities they chose, the authors offer an inspirational narrative, but also a model that others can adapt and apply to help ensure consistent considerations of diversity and equality in business schools.

Another key cohort of business schools consists of the next generation of educators, such that guiding them remains a critical consideration. The authors of "Guiding PhD Students," Di Benedetto, Lindgreen and Ringberg (Chapter 22), recall their PhD program experiences, noting their enthusiasm but also their lack of experience with research, insufficient teaching skills, and the incredible amount of time they had to devote to the program. The guidance provided by supervisors was critical, and inspired their own future efforts to emulate those supervisors and provide similar support to current students. Yet the challenges of $\mathrm{PhD}$ student supervision require more than simply mimicking others, so this chapter summarizes insights from various colleagues who collectively have supervised scores of $\mathrm{PhD}$ students who have gone on to successful academic careers, regarding what makes for effective $\mathrm{PhD}$ supervision. 


\section{PART VII: BRIDGING TEACHING, RESEARCH AND PRACTICE}

Finally, university teaching and supervision comes from academics who actively work to publish their cutting-edge insights, so education inevitably reflects research-related teaching materials, at least to some degree. For example, some research-based courses actually include students in the research process. When academics collaborate with students on projects, the students become co-creators of new research insights. If they adopt a teaching-based research approach, they might discuss research-based issues with students to gain new inspiration for their research. Beyond these efforts, in their attempts to meet societal demands for solutions to global issues, many universities seek collaborations with businesses and other societal actors. Thus, students might work together with practitioners to consider complex, diverse problems that the businesses lack the time or knowledge to resolve on their own. In some cases, such collaborations can lead to full-time positions for the students.

At research-intensive business schools in particular, a core of solid, productive researchers induces recognition and high rankings, as exemplified by the Financial Times business school rankings and the Bloomberg Business Week Best B-Schools Ranking. In "How to translate research into teaching," Lindgreen, Di Benedetto, Brodie and Naudé (Chapter 23) note that a few business schools (about 1 percent in total) receive accreditations from the Association to Advance Collegiate Schools of Business (AACSB), the Association of MBAs (AMBA) and the European Quality Improvement System (EQUIS), a recognition that attracts undergraduate and postgraduate students seeking to acquire the best capabilities and skills to ensure their career success, along with $\mathrm{PhD}$ students eager to function in strong research environments.

Moving away from research-dominant settings, Hains-Wesson, Cejnar, Ji, Shahbazi and Luksich (Chapter 24) detail an evaluation research project for a placement program that aims to encompass undergraduate and postgraduate business school degrees. With a mixed-methods evaluation, in "Work-integrated education: improving placement pedagogy and practice," they suggest options for improving the business school placement program. An online survey that gathered students' and industry partners' impressions of a placement effort revealed several relevant areas. For example, the learning activities, preparation and debrief workshops (integral to the program) needed to be better aligned in time with the work placement activity. Both students and industry respondents believed the assessments should be defined and conducted by the industry partners, which would help align students' efforts with organizational needs. The overall findings thus can be summarized in a set of specific practice recommendations for placement pedagogy.

To close out this Handbook, Seno-Alday (Chapter 25) offers a personal reflection: "On the busyness of business schools: harnessing synergy in research, teaching and engagement." Noting the pressures on academic to produce high-impact research, teach innovatively and engage productively with external stakeholders, all in a turbulent, rapidly and radically changing environment, the author offers some ideas for maintaining some balance and moving forward. Further informed by accounts by other scholars regarding how they have found synergy in research, teaching and engagement, she suggests practical tactics to leverage teaching and engagement to expand research, as well as to conduct research in a way that supports teaching and engagement. 


\section{CLOSING REMARKS}

We extend a special thanks to Edward Elgar Publishing and its staff, who have been most helpful throughout this entire process. Equally, we warmly thank our contributors with whom we have worked. They have exhibited the desire to share their knowledge and experience with the Handbook's readers, and a willingness to put forward their views for possible challenge by their peers. We hope that this Handbook of chapters and themes stimulates and contributes to colleagues in their teaching and learning.

\section{REFERENCES}

World Economic Forum (2019). The 4 biggest challenges to our higher education model - and what to do about them? https://www.weforum.org/agenda/2019/12/fourth-industrial-revolution-higher -education-challenges/. Accessed January 5, 2021. 
'The modernization of student learning experiences has never been more pressing than post-COVID.

This thought-provoking book provides a plethora of perspectives on how to achieve better and more modern learning, through teams, through technology, through cases and through the continuous professional development of educators. This volume is a useful handbook both for educational practitioners and for researchers in educational research and development. Highly recommended!' Peter Møllgaard, Maastricht University School of Business and Economics, the Netherlands

'Business education has experienced significant transformation in the 21st century, and more recently through the pressures on business schools to adapt to blended learning practices during the COVID-19 pandemic. This compilation of papers provides an excellent resource to help navigate and understand the important dimensions of successful modern business education. It includes contributions from some

leading scholars and across a range of important topics, including learning environments, technologies, CPD [continuing professional development] and research-led teaching.'

Stuart J. Barnes, King's College London, UK

'This book provides valuable direction to business schools during these transformational times. The chapters explore how business schools can improve the educational process, implement learning technologies, and effect pedagogical and social change.'

C. Anthony Di Benedetto, Temple University, Philadelphia, USA

'As we grapple with intensifying calls for change, this indispensable compendium poses critical questions whilst simultaneously offering valuable insights into the transformation journey that lies ahead for business school leadership and faculty.' Nicola Kleyn, Erasmus University, the Netherlands

'This is a much-needed compendium, bringing together contributions addressing a wide variety of aspects of business school teaching. It is a timely, original and interesting volume, written by educators and scholars based across the world. A must-read not only for those who are new to teaching but for everyone who wishes to keep abreast of pedagogic developments in business schools.'

Martyna Sliwa, University of Essex, UK and Co-Editor of Management Learning

'The book Handbook of Teaching and Learning at Business Schools: A Practice-Based Approach is a timeous and much needed book targeted at teaching faculty, administrators, and management of business schools across the globe. The book covers key issues business schools, irrespective of their geographic location, grapple with in ensuring an optimal learning experience for students. The book provides transformational perspectives of learning and gives insight into contemporary learning environments. The section on the use and value of learning technologies cannot come at a more opportune

time. The book also deals with aspects related to the teaching and assessing in the business school classroom, leadership education and professional development of teaching faculty. It concludes with a section addressing the translation of research into teaching, work integrated teaching and how to harness the synergies between research, teaching, and engagement. This is a must read as it provides deep insight into so many of the pertinent issues relevant to business school teaching and learning.'

Daniel J. Petzer, Henley Business School Africa, South Africa

'No other group of graduates has more access to resources than those with a business-oriented degree. How can universities prepare them for both the opportunities as well as the duties connected with such access? The authors of Handbook of Teaching and Learning at Business Schools: A Practice-Based

Approach have the pertinent answers for business educators of the current and next generation.'

Gregor Halff, Copenhagen Business School, Denmark

'Recent events have forced us to re-think how we undertake teaching and learning in business schools. This collection of essays on management education arrives at the perfect time to help us organize and enhance our thoughts about the changes underway, providing an overdue research perspective.'

Robert D. Austin, Ivey Business School, London, Canada 
'A timely and refreshing text!! Targeted at those who are eagerly seeking new ways of teaching and engaging students in challenging contexts. This book emphasises co-production of education, the importance of involving key stakeholders in the learning experience while ensuring leadership and professionalism remain core. This is a "must-read" for Business School faculty.' Julian Gould-Williams, Cardiff University, UK

'Business schools are in a unique position to both affect and effect change-socially, pedagogically, and developmentally. The perspectives on transformation, which highlight the many advantages and challenges which lie ahead, are rich with theoretical and practical examples. Consistently offering a student-centric approach, while recognising the demands placed on educators, is a delicate balancing act, but one which is clearly readily achieved here.' Juliette Overland, University of Sydney Business School, Australia 